\title{
Foundational Leadership Theory: The Inward and Outward Approach to Examine Ethical Decision-Making
}

\author{
La Juan Perronoski Fuller \\ Trident University International, Cypress, CA, USA \\ Email: lajuan.fuller@my.trident.edu
}

How to cite this paper: Fuller, L. P. (2021). Foundational Leadership Theory: The Inward and Outward Approach to Examine Ethical Decision-Making. Open Journal of Leadership, 10, 79-94.

https://doi.org/10.4236/ojl.2021.102006

Received: March 17, 2021

Accepted: June 4, 2021

Published: June 7, 2021

Copyright ( 2021 by author(s) and Scientific Research Publishing Inc. This work is licensed under the Creative Commons Attribution International License (CC BY 4.0).

http://creativecommons.org/licenses/by/4.0/

\begin{abstract}
Western societies tend to rely on societal norms to guide decision making. However, decisions based solely on societal norms may fluctuate between acceptable/unacceptable. As a result, leaders are paying heavy fines, asked to resign and in some cases found guilty in courts due to these fluctuations. This has become problematic for ethical leadership decision-making. This study introduces the foundational leadership theory which builds on ethic position theory by applying leader-member exchange concepts. Research confirmed that foundational leadership-integrity, assurance and pragmatism significantly predict organization commitment. Therefore, foundational leadership theory establishes employees' ethical perception of their leader and influences organizational commitment. CEOs, leaders, managers and supervisors should apply this foundational leadership model to evaluate ethical decision-making.
\end{abstract}

\section{Keywords}

Leadership Decision-Making, Decision-Making, Organizational

Commitment, Leadership, Moral and Ethical Decision-Making

\section{Introduction}

Western societies tend to rely more on social norms to govern morals and ethics (Reimer, et al., 2014). Additionally, leaders incorporate these norms to govern decision-making over organizational employees. However, this can become problematic due to rapid changes in society's definition of "what is acceptable/ unacceptable". As a result, we recognize more leaders paying heavy fines, forced to resign, or found guilty in courts because of rapid fluctuations in acceptable/ unacceptable ethical behavior. So, there is a need to establish a more reliable de- 
cision-making model to promote ethics and account for societal norms.

Employee perceptions of a leader's morals and ethics influence organizational behaviors. Additionally, Kellerman (2008) and Kottke (2013), confirm that follower perception, of a leader, is likely to influence employee behaviors toward the organization. As a result, leadership decision-making has shown to have a positive association with employees' commitment to the organization.

Organizational commitment is defined as an employee's psychological bond with their organization and measured by affective, continuance, and normative commitment (Choi et al. 2015). So, the social science community widely accepts that follower perceptions of a leader's ethics influence commitment to the organization. Thus, it is beneficial examine leadership's ethical decision-making using both a personal an employee-centered approach.

This study introduces the Foundational leadership theory. Foundational leadership theory suggests that leaders should conduct an inward (personal) and outward (employee perception) examination measure by integrity, assurance and pragmatism. Leadership decision-making based on this approach should establish an ethical guideline and promote organizational commitment. Therefore, if foundational leadership theory establishes ethical decision-making, then employees are more likely to have a positive association with organization commitment.

Research Question(s)

R1: Does foundational leadership integrity, assurance and pragmatism influence organizational commitment?

\section{Literature Review}

Foundational Leadership Theory (FLT) builds on the Ethic Position Theory (Forsyth, 1980, 1992) grounded on the work of Kohlberg (1976) and Piaget (1932). Ethic position theory explains that moral actions and evaluations are outward expressions of a person's integrated conceptual system of personal ethics or ethical position. Moral philosophy has a significant influence on feelings, decisions and behaviors in typical sensitive ethical scenarios. Ethics Position Theory presents "idealism" and "relativism" as the two major dimensions in ethical ideology. Idealism and relativism are dissimilar and may affect individual behavior in different situations.

Idealistic decision-makers show concern for the welfare of others. Whereas highly idealistic individuals feel that harming others is almost always avoidable (Forsyth, 1992). Decision-makers that are high in idealism generally will avoid decisions or actions that harm others. The theory is grounded on serving others, compliance with both moral principles and values. They are highly associated with ethics in caring for others. Relativism is the degree an individual complies with moral rules and regulations for decision-making in the workplace. The rules and regulations include values and action such as avoiding fraud, humiliating and speaking the truth. Individuals that score high in relativism tend to evaluate situations and the outcome rather than focusing on moral principles. 


\subsection{Ethical Leadership on Organizational Commitment}

Over the past decade, adaptation of systematic approaches to examine ethical leadership meanings and consequences has been given more attention (Hassan et al., 2014; Fehr et al., 2015). For example, ethical leadership has a positive relationship with a leader's integrity and consideration of fairness (Miao et al., 2013). Additionally, ethical leadership improves affective commitment (Brown et al., 2005), influences followers attitudes toward the job (Yukl, 2013) and satisfaction with their leaders (Guchait et al., 2016). These behaviors and attributes promote trust and considered a major contributor toward employee job satisfaction (Engelbrecht et al., 2017). As a result, ethical leadership has become an important motivational resource which improves employee commitment and job satisfaction (Chen, 2017; Qing et al., 2019).

However, managerial responsibility has been called into question more often in the corporate world. So, responsible leadership practices have received much attention in the organizational studies academic fields. Waldman and Galvin (2008) suggested that leadership responsibility was missing from established descriptors such as transformational, authentic, spiritual and ethical leadership. Additionally, Miska and Mendenhall (2015) confirmed and revealed a significance between leadership ethical responsibility and organizational commitment. So, leaders who better engage employees are likely to reduce turnover intentions and improve organizational commitment (Haque et al., 2019).

\subsection{Leader-Member Exchange on Organizational Commitment}

The Social Norm Theory (SNT) is applied to understand the connection between peer influencing decision-making. Hogg and Reid (2006) research build on SNT and concludes that norms serve as a functional purpose providing individuals with guidelines and rules of thumb regarding how to think and act in various situations. Thus, a person's morals and ethics develop through conformity and approval of those actions. However, this process does not account for proper behaviors and appropriate actions in the leader-member exchange process.

Leader-member exchange (LMX) measures the quality of the relationship between leader and subordinate which includes attributes such as trust and understanding (Darrat et al., 2016). Additionally, LMX has a significant relationship with follower perception and organizational commitment (Harris et al., 2011; Keskes et al., 2018). As a result, studies reveal that LMX reduces job insecurity, job stress and employee turnover (Darrat et al., 2016; Probst et al., 2016). FLT applies LMX to account for follower perceptions. Thus, leadership ethical decision-making is measured by outward examinations (employee perception) of leadership integrity, assurance, and pragmatism.

\subsection{Foundational Leadership-Integrity}

Integrity is known as the foundation of organizational and societal justice. McGregor (1960) research reveal fairness relates to ethical leadership and affects 
organization and social justice. Brown and Trevino (2005) confirm these results and concludes that fair decision-making is the primary procedural aspect of ethical leadership. Ethical decision-making involves discussing with employees what the right course of action is and acting with the best interest of the employee in mind (Brown et al., 2005). Ethical leaders are viewed as having integrity when they are trustworthy, caring, honest and fair (Jordan et al., 2017) which enhances follower perception of empowerment that mediates organizational commitment (Ming et al., 2020).

Ethical leadership continues to positive effect on organizational commitment (Yang \& Wei, 2017). Thus, the initial decision examination begins with Foundational Leadership-Integrity (FL-I). Integrity is a significant component of effective leadership and has been the primary subject of leadership for over 5 decades (Palanski \& Yammarino, 2009). There has yet to be a shared understanding of integrity causing it to be considered vague and ill-defined (Palanski \& Yammarino, 2009; Parry \& Proctor-Thomson, 2002; Leicht-Deobald, Busch, Schank, Weibel, Schafheitle, Wildhaber, \& Kasper, 2019). Nevertheless, individuals with a high/strong moral-self are more attentive and motivated to act and make ethical decisions (Jennings, Mitchell \& Hannah, 2014). However, due to the lack of shared understanding of integrity, FL-I introduces 5-items for decision integrity and measures the concept based on promoting organizational commitment.

\subsection{Foundational Leadership-Assurance}

Foundational Leadership-Assurance (FL-A) is the second phase of FLT. Moral sensitivity strongly influences moral stress (Sparks \& Hunt, 1998; Reynolds, 2008; Daniels, Diddams, \& Van Duzer, 2011). Trevino et al., (2003) contributes to research in moral stress by examining factors that influence employee anxiety and uncertainty. Results reveal that ethical leadership reduces anxiety and stress. Additionally, Brown et al. (2005) found that it was vital that leaders use ethical decision-making for greater effectiveness and efficiency of organizational members. Employees experience different in the levels of job stress. However, high stress reduces productivity and decreases job performance (Halkos \& Bousinkas, 2010; Shahid et al., 2012; Shukla \& Srivastava, 2016). Therefore, FL-A integrates employee perception of moral and ethical leadership decisions based on stress, anxiety, and uncertainty.

Furthermore, leadership quality correlates with employee self-perception health (Tepper, 2007); well-being (Arnold et al., 2007), motivation, contentment/commitment and performance (Söderfjell, 2007) and team co-operation (Gundersen et al., 2012). So, attention and focus on moral issues and moral sensitivity enhances reflective moral attentiveness, awareness, idealism and identity (Lützén, Blom, ewalds-Kvist, \& Winch, 2010). Thus, FL-A is likely to contribute to organizational commitment.

\subsection{Foundational Leadership-Pragmatism}

The Social Exchange Theory (SET) suggests that one size approach does not fit 
all and label pragmatism as fundamental to decision-making (Homans, 1961, 1974). Additionally, pragmatism appears most in organizational routines (Winter, 2013) and reflective practice (Jordan, 2010). However, in the past decade, pragmatism has entered into the field of business ethics (Jensen and Sandstrom, 2013). Thus, pragmatism is introduced to measure the employee's perception on decisions that help employee's meet personal and professional goals.

Pragmatic forms of ethical leadership also improve employee dedication based on SET (Anderson \& Sun, 2017). So, decisions perceived as pragmatic are likely to improve leadership decision-making capabilities and increase employee commitment to the organization. Thus, foundational leadership-pragmatism (FL-P) suggests employees should perceive decisions will help them meet or exceed organizational goals thereby influences organizational commitment.

\subsection{Organizational Commitment}

Meyer and Allen (1997) organizational commitment model dominate organizational commitment research (Meyer et al., 2002). The research findings reveal that employees experience affective, normative and continuance organizational commitment. This has become the most widely used measurement of organizational commitment. Current research confirmed that organizational commitment represents the psychological bond between an employee and the organization (Choi et al., 2015). Thus, affective commitment (AC) explains the emotional ties developed between the employee and organization. Normative Commitment (NC) describes how employees perceived their obligation and duty to the organization. Continuance Commitment (CC) depicts employee economic and social cost to stay or leave an organization. However, employee perceptions of their leader significantly influence AC, NC, and CC.

Meyer and Allen (1997) organizational commitment model have been used in countless research to significantly predict citizenship behaviors, job performance, absenteeism and tardiness (Meyer et al., 2002). Comparatively, moral and ethical leadership had no affect in studies by Erben and Guneser's (2008) study on organizational commitment. However, reciprocal interactions between the leader and employee improves commitment to the organization (Schuh et al., 2013; Chen et al., 2014). Furthermore, collective efficacy is an important organizational property within an organization. This relates to employee belief in the team's capability to execute and meet goals and objectives. Chen et al., (2019) confirms that collective efficacy explains why leadership generates high levels of organizational commitment. Thus, FLT focuses on internal and outward expressions of a leader's decision making capabilities measured by employee perceptions of foundational leadership-integrity, assurance and pragmatism. This study will incorporate Meyer and Allen (1997) model to measure the overall relationship with organization commitment (Figure 1).

H1: Foundational leadership theory has a positive association with organization commitment. 


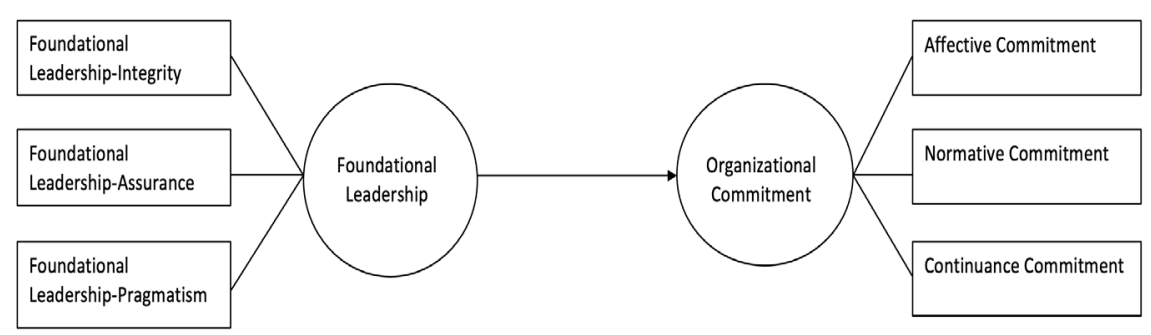

Figure 1. Foundational leadership theory conceptual model.

\section{Methodology}

This chapter describes the overall validity and reliability of the independent variable (IV) FLT and dependent variable (DV) organizational commitment. The chapter designates the approach to generate, collect, and analyze data for this investigation. This cross-sectional, quantitative study collected and analyzed data to study the relationship between FLT and organizational commitment. The independent variable (IV) is foundational leadership and dependent variable (DV) is organizational commitment. The IV is based on a 15 -item scale that measured foundational leadership-integrity (5-items), assurance (5-items), and pragmatism (5-items). The survey asked respondents to indicate level of agreement to each item (strongly disagree, disagree, slightly disagree, neither agree nor disagree, slightly agree, agree, strongly agree).

\subsection{Definition of Terms}

FLT suggest leaders should consider both inward and outward examination of decisions to govern decision-making in addition to societal norms. FLT provide guidelines to address perceived integrity, assurance and pragmatism of decisions. Decisions grounded in FLT will significantly predict employee organizational commitment. FLT consist of 15-items combining FL-I (5-items), FL-A (5-items) and FL-P (5-items) using a seven-point Likert typed measurement scale.

\subsection{Foundational Leadership-Integrity}

Integrity creates perceived fairness which significantly relates to ethical leadership and affects organization and social justice (McGregor, 1960). Thus, FL-I is measured using a 5-item scale and indicated their extent of agreement with each item on a seven-point Likert-typed scale ( $1=$ strongly agree, $7=$ strongly disagree). For example 1) My leader's decisions should NOT be based on receiving personal gifts and/or money. 2) My leader's decisions should NOT be based on unsupported personal opinions. 3) My leader's decision should NOT be based on receiving personal favors in return.

\subsection{Foundational Leadership-Assurance}

Leadership decisions are grounded in FL-A when leadership choices reassure organizational employees. FL-A is measured using a 5-item scale. The respon- 
dents indicated their extent of agreement with each item on a seven-point $\mathrm{Li}$ kert-typed scale ( $1=$ strongly agree, $7=$ strongly disagree). For example 1$)$ I trust leadership decisions that promote job security. 2) I trust leadership decisions that consider the amount of anxiety their decisions may cause. 3) I trust leadership decisions when they are not confusing, unclear and uncomplicated.

\subsection{Foundational Leadership-Pragmatism}

Leadership decisions are grounded in FL-P when choices are practical, easy to understand and help employees met professional and organizational goals. The respondents indicated their extent of agreement with each item on a seven-point Likert-typed scale ( 1 = strongly agree, $7=$ strongly disagree). For example 1$)$ I believe leadership decisions should help employees meet and/or exceed organizational goals. 2) I believe leadership decisions should be realistic and achievable on the job. 3) I should be able to apply leadership decisions on the job.

\subsection{Organizational Commitment}

OC has been identified as a multi-dimensional associated with workplace performance and affective commitment (Wright \& Bonett, 2002). The 15-item OC Likert scale was adopted from Meyer and Allen (1990). The respondents indicated their extent of agreement with each item on a seven-point Likert-Typed scale $(1=$ strongly agree, 7 = strongly disagree). For example 1$)$ I feel a strong sense of belonging to my organization. 2) Right now, staying with my organization is a matter of necessity as much as desire. 3) I would feel guilty if I left this organization now.

\subsection{Method of Analysis}

The sample for this study consisted of fulltime workforce employees in the United States. Employees were contacted via the Internet-based survey application. In the 504 completed surveys, 491 agreed to participate in the survey. Out of 491, 403 respondents provided demographic information. Data cleaning was conducted and 396 total employee surveys were used to conduct this investigation. The sample consisted of $46.40 \%$ males and $53.60 \%$ females.

This cross-sectional, quantitative study collected and analyzed data to study independent variable agent based leadership decision-making relationship between dependent variables affective commitment, continuance commitment and normative commitment.. Dependent variables were based on multi-dimensional association with workplace performance and affective commitment (Wright \& Bonett, 2002) and adopted scale from Meyer and Allen (1990). The survey asked respondents to indicate level of agreement to each item (strongly disagree, disagree, slightly disagree, neither agree nor disagree, slightly agree, agree, strongly agree).

The results from this study were based on IBM SPSS Statistics 25's Cronbach's alpha, Pearson correlation and linear regression output for FL-I, FL-A, FL-P and organizational commitment scale by Meyer and Allen (1997). The sample for 
this study consisted of fulltime employees within the United States. The research followed general procedures of linear regression. Pretests were established because FL-I, FL-A, FL-P were developed for to measure the accuracy of this theory. The pretest concluded that Cronbach's alpha measured FL-I $=0.885$, FL-A $=0.811$, and FL-A $=0.904$ which exceeds the acceptable measurement for scale reliability of the Likert-type scales George and Mallery (2016) where $>0.9$ excellent, $>0.8$ good, $>0.7$ acceptable, $>0.6$ questionable, $>0.5$ poor, and $<0.5$ unacceptable.

Cronbach's alpha was used to measure scale reliability of the Likert-type scales. Pearson correlation was used to represent relationships between the IV and DV. The results tested the assumptions of normality, homoscedasticity, outliers and regression paths. Since there was only one predictor variable, multicollinearity does not apply, and Variance Inflation Factors (VIF) were not calculated. The research followed general procedures for regression analysis. Linear regression analysis was used to compare the positive or negative strength between the IV and DVs. Linear regression provided the necessary confirmation for this measurement model. Pearson correlation was used to determine the relationship represent relationships between the IV and DV.

\section{Results}

Summary statistics were calculated for CC, NC, AC, FL-A, FL-I, FL-P. Each variable is within skewness and kurtosis ranges. When the skewness is between -2 and 2 in absolute value, the variable is considered to be symmetrical about its mean. When the kurtosis is between -3 and 3 , then the variable's distribution is normally distribution and the tendency to be free of outliers (Westfall \& Henning, 2013). The summary statistics can be found in Table 1 .

A Cronbach alpha coefficient was calculated for each IV and DV. The Cronbach's alpha coefficient was evaluated using the guidelines suggested by George and Mallery (2016) where $>0.9$ excellent, $>0.8$ good, $>0.7$ acceptable, $>0.6$ questionable, $>0.5$ poor, and $<0.5$ unacceptable. Each construct loaded $>0.8$, indicating good reliability. Each construct as measured above $>0.8$ indicating good reliability Because of good reliability, FL-I, FL-A and FL-P were computed into the FLT and AC, CC, and NC into OrgComit. Table 2 presents the results of the reliability analysis.

A Pearson correlation analysis was conducted between FLT and OrgComit using Cohen's standard to evaluate the strength of the relationship, where coefficients between 0.10 and 0.29 represent a small effect size, coefficients between 0.30 and 0.49 represent a moderate effect size, and coefficients above 0.50 indicate a large effect size (Cohen, 1988). The correlations were examined using Holm corrections to adjust for multiple comparisons based on an alpha value of 0.05.

A significant positive correlation was observed between FLT and OrgComit. This correlation indicates that as FLT increases, OrgComit tends to increase. Linear regression will be conducted to determine if FLT significantly predicts OrgComit. Table 3 presents the results of the correlations. 
Table 1. Summary statistics table for interval and ratio variables.

\begin{tabular}{ccccccccc}
\hline Variable & $\mathrm{M}$ & $\mathrm{SD}$ & $\mathrm{n}$ & $\mathrm{SE}_{\mathrm{M}}$ & $\mathrm{Min}$ & $\mathrm{Max}$ & Skewness & Kurtosis \\
\hline FL-I & 25.55 & 7.27 & 396 & 0.37 & 5.00 & 35.00 & -0.59 & -0.40 \\
FL-A & 26.68 & 5.66 & 396 & 0.28 & 5.00 & 35.00 & -0.79 & 0.62 \\
FL-P & 32.21 & 6.99 & 396 & 0.35 & 6.00 & 42.00 & -0.66 & 0.17 \\
AC & 18.35 & 5.76 & 396 & 0.29 & 4.00 & 28.00 & -0.37 & -0.39 \\
NC & 21.04 & 7.10 & 396 & 0.36 & 5.00 & 35.00 & -0.22 & -0.44 \\
CC & 26.70 & 7.51 & 396 & 0.38 & 6.00 & 42.00 & -0.31 & -0.29 \\
\hline
\end{tabular}

Table 2. Reliability table for FLT decision-making and OrgComit.

\begin{tabular}{ccccc}
\hline Variable & Item & $\boldsymbol{\alpha}$ & Lower Bound & Upper Bound \\
\hline FL-I & 5 & 0.88 & 0.87 & 0.90 \\
FL-A & 5 & 0.90 & 0.89 & 0.92 \\
FL-P & 5 & 0.81 & 0.78 & 0.84 \\
AC & 4 & 0.86 & 0.87 & 0.90 \\
NC & 5 & 0.87 & 0.85 & 0.89 \\
CC & 6 & 0.81 & 0.79 & 0.84 \\
\hline
\end{tabular}

Table 3. Pearson correlation results for FLT and OrgComit.

\begin{tabular}{ccccc}
\hline Combination & $\mathrm{r}_{\mathrm{p}}$ & Lower & Upper & $p$ \\
\hline FLT-OrgComit & 0.51 & 0.43 & 0.58 & $<0.001$ \\
\hline
\end{tabular}

${ }^{*}$ Note. The confidence intervals were computed using $\alpha=0.05 ; \mathrm{n}=396$; Holm corrections used to adjust $p$-values.

Linear regression analysis was conducted to assess whether FLT significantly predicted OrgComit. The assumption of normality was assessed by plotting the quantiles of the model residuals against the quantiles of a Chi-square distribution, also called a Q-Q scatterplot (DeCarlo, 1997). The assumption of normality was met and quantiles of the residuals did not strongly deviate from the theoretical quantiles. This represents reliable parameter estimates.

Homoscedasticity. Homoscedasticity was evaluated by plotting the residuals against the predicted values (Bates et al., 2014; Field, 2013; Osborne \& Walters, 2002). The assumption of homoscedasticity was met because the points appear randomly distributed with a mean of zero and no apparent curvature.

Multicollinearity. Since there was only one predictor variable, multicollinearity does not apply, and Variance Inflation Factors were not calculated.

Results. The results of the linear regression model were significant for the IV and DV. FLT significantly predicted OrgComit. FLT explained approximately $43 \%$ of the variance in OrgComit. Table 4 summarizes the results of the regression model.

Table 5 and Figure 2 summarizes the hypothesis results for FLT and OrgComit. 
Table 4. Linear regression results for FLT and OrgComit.

\begin{tabular}{ccccccc}
\hline Variable & B & SE & CI & $\beta$ & t & $p$ \\
\hline FLT: OrgComit & 0.43 & 0.04 & {$[0.36,0.51]$} & 0.51 & 11.64 & $<0.001$ \\
\hline
\end{tabular}

Table 5. Hypothesis testing results for FLT and OrgComit.

\begin{tabular}{llll}
\multicolumn{1}{c}{ Variable } & $\mathrm{B}$ & $\mathrm{SE}$ \\
\hline \multicolumn{1}{c}{$\mathrm{H1:}$ FLT significantly predicts organizational commitment } & $P<0.001$ & Accepted \\
\hline $\begin{array}{l}\text { Foundational } \\
\text { Leadership-Integrity }\end{array}$ \\
\hline $\begin{array}{l}\text { Foundational } \\
\text { Leadership-Assurance } \\
\text { Leadership-Pragmatism }\end{array}$
\end{tabular}

Figure 2. Foundational leadership theory operational model.

\section{Discussion}

Ethic Position Theory establishes moral actions and evaluation as outward expressions of the decision-maker ethical position (Forsyth, 1980, 1992). Additionally, follower perception, of the leader, influences employee behaviors toward the organization (Kellerman, 2008; Kottke, Pelletier, \& Agars, 2013). FLT contributes to this literature by revealing that foundational leaders who consider inward (the self) and outward expressions (employee perception) has a significant positive relationship with organizational commitment.

Furthermore, there has yet to be a shared understanding of integrity. As a result, this created a vague and ill-defined term for decision-makers (Palanski \& Yammarino, 2009; Parry \& Proctor-Thomson, 2002; Leicht-Deobald, Busch, Schank, Weibel, Schafheitle, Wildhaber, \& Kasper, 2019). However, this research contributes to this gap in knowledge and establishes decision integrity based on employee perceptions of the 5-items measured in this study. Thus, decisions measured by FL-I are in the best interest of the organization and less likely perceived by employees as for personal gain or for self.

FL-A contributes to research on employee self-perception health (Tepper, 2007); well-being (Arnold et al., 2007), motivation, contentment/commitment by supportive leadership (Söderfjell, 2012; Tafvelin et al., 2019) and team cooperation (Gundersen et al., 2012). Thus, employee perception of leadership attention to moral issues and moral sensitivity enhances moral attentiveness, awareness, idealism and identity (Lützén et al., 2010). This research confirms FL-A contributes to organizational commitment by measuring employees' perception on how well leadership decisions promote assurance. 
FL-P incorporated the Social Exchange Theory (SET) by incorporating pragmatism by Homans (1961, 1974) and Anderson and Sun (2017). Comparatively, pragmatic forms of ethical leadership establish dedication to others and addresses the one size does not fit approach. Thus, FL-P confirms that employees who perceive leadership decisions as practical, realistic and achievable is positively associated with organizational commitment.

Leadership decisions are foundational and should align employees with the overall goals of organization. Therefore, leaders should use examine decisions using inward and outward measurements before implementing on organizational employees. For example, if the leaders determine a decision was decided due to receiving personal gain, favors or to deceive, then the decision should not be implemented. Comparatively, if employees perceived decisions are for personal gain or favors, then leaders should implement a communication plan to inform of intent, to reassure, and enlighten employees how it applies to the job. So, leaders should incorporate FLT to provide an additional layer of protection to account for employee perceptions of their decisions. Therefore, leaders are more likely to improve employee perceptions of their decisions thereby creating organization commitment.

\section{Conclusion}

This research provided a systematic approach to leadership decision-making. The results indicated that FLT has a positive association to organizational commitment. Thus, organization leaders can improve organizational commitment by measuring decisions using foundational leadership-integrity, assurance and pragmatism.

This study concludes that foundational leadership theory provides a measurable framework that suggests employees who perceive leadership decisions fair (FL-I), reduce anxiety and stress (FL-A), and help met professional and organizational goals creates commitment to the organization. As a result, decisions measured by these constructs enhance follower perceptions of leaderships' ethical decision-making abilities. Thus, organization leaders should consider using FLT in addition to ensure that decisions are not solely reliant on societal norms to guide moral and ethical decision-making.

\subsection{Limitations, Delimitations, and Significance}

This research involved limitations in using cross-sectional study methods. This approach cannot measure change in employee organizational relationship over time. Employees in this study may yield different results in changes in societal norms of acceptable moral and ethical behavior. To measure change in FLT and organizational commitment, it would be beneficial to have additional cross-sectional studies of the same US population sample groups.

The investigation could not measure the entire population. Data were collected from a subset of employees, and there may be differences between the 
sample and the population. Permission letters were sent to the study population through online survey method. Employees may have rushed or may not have fully answered each question to the best of their knowledge. To mitigate this error, the measurement scale contained only 36 one-sentence items to address all variables in the study. The organizational commitment items were derived from previous validated and accepted studies to decrease survey item bias. FLT measurement scale was sent to a test group before overall testing scale was sent to the sample population. The measurement scale met acceptable Cronbach alpha levels in both cases.

\subsection{Future Research}

Changes in societal norms may change acceptable moral and ethical behavior. Therefore, longitudinal studies should be conducted to measure FLT resistance to these norm changes. Additionally, studies on FLT's mediating and moderating effect on leadership styles would provide more understanding into improving organizational commitment. The ability to learning more about mediating and moderating effects of FLT on leadership styles may assist leaders, managers, and supervisors in understanding methods that influence employee intentions to stay with the organization.

Gender and age showed no significant effects on FLT and organizational commitment. Therefore, future research should consider race and sexual orientation on FLT association with organizational commitment. This would assist leaders, managers, and supervisors to understand more about employee perception of leadership decision-making capabilities and organizational commitment.

\section{Conflicts of Interest}

The author declares no conflicts of interest regarding the publication of this paper.

\section{References}

Anderson, M., \& Sun, P. (2017). Reviewing Leadership Styles: Overlaps and the Need for a New Full Range Theory. International Journal of Management Reviews, 19, 76-96. https://doi.org/10.1111/ijmr.12082

Arnold, K. A., Turner, N., Barling, J., Kelloway, E. K., \& McKee, M. C. (2007). Transformational Leadership and Psychological Well-Being: The Mediating Role of Meaningful Work. Journal of Occupational Health Psychology, 12, 193-203. https://doi.apa.org/doi/10.1037/1076-8998.12.3.193

Bates, D., Mächler, M., Bolker, B., \& Walker, S. (2014). Fitting Linear Mixed-Effects Models Using Lme4. Journal of Statistical Software, 67, 1-48. http://doi.org/10.18637/jss.v067.i01

Brown, M., \& Trevino, L. (2005). Ethical Leadership: A Social Learning Perspective for Construct Development and Testing. Organizational Behavior and Human Decision Processes, 97, 117-134. https://doi.org/10.1016/j.obhdp.2005.03.002

Brown, M. E., Trevino, L. K., \& Harrison, D. A. (2005). Ethical Leadership: A Social Learning Perspective for Construct Development and Testing. Organizational Behavior and 
Human Decision Processes, 97, 117-134.

https://doi.org/10.1016/j.obhdp.2005.03.002

Chen, H. W. (2017). An Empirical Analysis of the Influence of Civil Servants' Psychological Empowerment and Job Satisfaction on Organizational Citizenship Behavior for the Environment. http://doi.org/10.1108/md-09-2018-0966

Chen, X. P., Eberly, M. B., Chiang, T. J., Farh, J. L., \& Cheng, B. S. (2014). Affective trust in Chinese Leaders Linking Paternalistic Leadership to Employee Performance. Journal of Management, 40, 796-819. https://doi.org/10.1177\%2F0149206311410604

Chen, Y., Zhou, X., \& Klyver, K. (2019). Collective Efficacy: Linking Paternalistic Leadership to Organizational Commitment. Journal of Business Ethics, 159, 587-603. https://doi.org/10.1007/s10551-018-3847-9

Choi, D., Oh, I. -S., \& Colbert, A. E. (2015). Understanding Organizational Commitment: A Meta-Analytic Examination of the Roles of the Five-Factor Model of Personality and Culture. Journal of Applied Psychology, 100, 1542-1567.

https://doi.apa.org/doi/10.1037/apl0000014

Cohen, J. (1988). Statistical Power Analysis for the Behavior Sciences (2nd ed.). St. Paul, $\mathrm{MN}$ : West Publishing Company.

Daniels, D., Diddams, M., \& Van Duzer, J, (2011). A Magnetic Pull on the Internal Compass: The Moderating Effect of Response to Culture on the Relationship Between Moral Identity and Ethical Sensitivity. Journal of Religion and Business Ethics, 2, Article No. 3. https://via.library.depaul.edu/jrbe/vol2/iss2/3.

Darrat, M., Atinc, G., \& Babin, B. J. (2016). On the Dysfunctional Consequences of Salesperson Exhaustion. Journal of Marketing Theory and Practice, 24, 236-245. https://doi.org/10.1080/10696679.2016.1130563

DeCarlo, L. T. (1997). On the Meaning and Use of Kurtosis. Psychological Methods, 2, 292-307. https://doi.apa.org/doi/10.1037/1082-989X.2.3.292

Engelbrecht, A. S., Heine, G., \& Mahembe, B. (2017). Integrity, Ethical Leadership, trust and Work Engagement. Leadership \& Organization Development Journal, 38, 368-379. https://doi.org/10.1108/LODJ-11-2015-0237

Erben, G. S., \& Günes,er, A. B. (2008). The Relationship between Paternalistic Leadership and Organizational Commitment: Investigating the Role of Climate Regarding Ethics. Journal of Business Ethics, 82, 955-968. https://doi.org/10.1007/s10551-007-9605-Z

Fehr, R., Yam, K. C. S., \& Dang, C. (2015). Moralized Leadership: The Construction and Consequences of Ethical Leader Perceptions. Academy of Management Review, 40, 182209. https://doi.org/10.5465/amr.2013.0358

Field, A. (2013). Discovering Statistics Using SPSS (4th ed.). Thousand Oaks, CA: Sage.

Forsyth, D. R. (1980). A Taxonomy of Ethical Ideologies. Journal of Personality and Social Psychology, 39, 175-180. https://content.apa.org/doi/10.1037/0022-3514.39.1.175

Forsyth, D. R. (1992). Judging the Morality of Business Practices: The Influences of Personal Moral Philosophies. Journal of Business Ethics, 11, 461-470. https://doi.org/10.1007/BF00870557

George, D., \& Mallery, P. (2016). SPSS for Windows Step by Step: A Simple Guide and Reference. Boston, MA: Allyn and Bacon. https://doi.org/10.4324/9781315545899

Guchait, P., Simons, T., \& Pasamehmetoglu, A (2016). Error Recovery Performance: The Impact of Leader Behavioral Integrity and Job Satisfaction. Cornell Hospitality Quarterly, 57, 150-161. https://doi.org/10.1177\%2F1938965515613858

Gundersen, G., Hellesøy, B. T., \& Raeder, S. (2012). Leading International Project Teams: The Effectiveness of Transformational Leadership in Dynamic Work Environments. Jour- 
nal of Leadership \& Organizational Studies, 19, 46-57.

https://doi.org/10.1177\%2F1548051811429573

Halkos, G., \& Bousinakis, D. (2010). The Effect of Stress and Satisfaction on Productivity. International Journal of Productivity and Performance Management, 59, 415-431. https://doi.org/10.1108/17410401011052869

Haque, A., Fernando, M., \& Caputi, P. (2019). The Relationship between Responsible Leadership and Organisational Commitment and the Mediating Effect of Employee Turnover Intentions: An Empirical Study with Australian Employees. Journal of Business Ethics, 156, 759-774. https://doi.org/10.1007/s10551-017-3575-6

Harris, K. J., Wheeler, A. R., \& Kacmar, K. M. (2011). The Mediating Role of Organizational Job Embeddedness in the LMX-Outcomes Relationships. The Leadership Quarterly, 22, 271-281. https://doi.org/10.1016/j.leaqua.2011.02.003

Hassan, M. S., Abdul Rahman, R., \& Hossain, S. Z. (2014). Monitoring Family Performance: Family Ownership and Corporate Governance Structure in Bangladesh. Procedia-Social and Behavioral Sciences, 145, 103-109. https://doi.org/10.1016/j.sbspro.2014.06.016

Hogg, M.A., \& Reid, S.A. (2006) Social Identity, Self-Categorization, and the Communication of Group Norms. Communication Theory, 16, 7-30. https://doi.org/10.1111/j.1468-2885.2006.00003.x

Homans, G. C. (1961). Social Behavior: Its Elementary Forms. San Diego, CA: Harcourt Brace Jovanovich.

Homans, G. C. (1974). Social Behavior: Its Elementary Forms (Revised ed.). San Diego, CA: Harcourt Brace Jovanovich.

Jennings, P., Mitchell, M., \& Hannah, S. (2014). The Moral Self: A Review and Integration of the Literature. Journal of Organizational Behavior, 36, 104-168. https://doi.org/10.1002/job.1919

Jensen, T., \& Sandstrom, J. (2013). In Defense of Stakeholder Pragmatism. Journal of Business Ethics, 114, 225-237. https://doi.org/10.1007/s10551-012-1338-y

Jordan, G., Miglič, G., Todorović, I., \& Marič, M. (2017). Psychological Empowerment, Job Satisfaction and Organizational Commitment among Lecturers in Higher Education: Comparison of Six CEE Countries. Organizacija, 50, 17-32. https://doi.org/10.1515/orga-2017-0004

Jordan, S. (2010). Learning to Be Surprised: How to Foster Reflective Practice in a HighReliability Context. Management Learning, 41, 391-413. https://doi.org/10.1177\%2F1350507609357388

Kellerman, B. (2008). Followership: How Followers Are Creating Change and Changing Leaders. Boston, MA: Harvard Business Press.

Keskes, I., Sallan, J., Simo, P., \& Fernadez, V. (2018) Transformational Leadership and Organizational Commitment: The Mediating role of Leader-Member Exchange. Journal of Management Development, 37, 271-284.

https://doi.org/10.1108/JMD-04-2017-0132

Kohlberg, L. (1976). Moral Stages and Moralization: The Cognitive-Developmental Approach. In T. Lickona (Ed.), Moral Development and Behavior: Theory, Research and Social Issues (pp. 31-53). New York, NY: Holt, Rinehart and Winston.

Kottke, J. L., Pelletier, K. L., \& Agars, M. D. (2013). Measuring Follower Confidence in Top Leadership Direction. Leadership \& Organization Development Journal, 34, 292 307. https://doi.org/10.1108/LODJ-07-2011-0062

Leicht-Deobald, U., Busch, T., Schank, C., Weibel, A., Schafheitle, S., Wildhaber, I. et al. 
(2019). The Challenges of Algorithm-Based HR Decision-Making for Personal Integrity. Journal of Business Ethics, 160, 377-392.

https://doi.org/10.1007/s10551-019-04204-w

Lützén, K., Blom, T., Ewalds-Kvist, B., \& Winch, S. (2010). Moral Stress, Moral Climate and Moral Sensitivity among Psychiatric Professionals. Nursing Ethics, 17, 213-224. https://doi.org/10.1177\%2F0969733009351951

McGregor, D. (1960). The Human Side of Enterprise. New York: McGraw-Hill

Meyer, J., \& Allen, N. (1997). Commitment in the Workplace: Theory, Research, and Application. Thousand Oaks, CA: Sage Publications.

Meyer, J.P., Stanley, D.J., Herscovitch, L., \& Topolnytsky, L. (2002). Affective, Continuance, and Normative Commitment to the Organization: A Meta-Analysis of Antecedents, Correlates, and Consequences. Journal of Vocational Behavior, 61, 20-52. https://doi.org/10.1006/jvbe.2001.1842

Miao, Q., Newman, A., Yu, J., \& Xu, L. (2013). The Relationship between Ethical Leadership and Unethical Pro-Organizational Behavior: Linear or Curvilinear Effects? Journal of Business Ethics, 116, 641-653. https://doi.org/10.1007/s10551-012-1504-2

Ming, X., Bai, X., \& Lin, L. (2020). Kick the Cat: A Serial Crossover Effect of Supervisors' Ego Depletion on Subordinates' Deviant Behavior. Frontiers in Psychology, 11, 1-11. https://doi.org/10.3389/fpsyg.2020.01314

Miska, C., \& Mendenhall, M. E. (2018). Responsible Leadership: A Mapping of Extant Research and Future Directions. Journal of Business Ethics, 148, 117-134. https://doi.org/10.1007/s10551-015-2999-0

Osborne, J., \& Waters, E. (2002). Four Assumptions of Multiple Regression That Researchers Should Always Test. Practical Assessment, Research \& Evaluation, 8, Article No. 2.

Palanski, M. E., \& Yammarino, F. J. (2009). Integrity and Leadership: A Multi-Level conceptual framework. Leadership Quarterly, 20, 405-420. https://doi.org/10.1016/j.leaqua.2009.03.008

Parry, K. W., \& Proctor-Thomson, S. B. (2002). Perceived Integrity of Transformational Leaders in Organisational Settings. Journal of Business Ethics, 35, 75-96. https://doi.org/10.1023/A:1013077109223

Piaget, J. (1932). The Moral Judgment of the Child. Glencoe, IL: Free Press, 1948.

Probst, T. M., Jiang, L., \& Graso, M. (2016). Leader-Member Exchange: Moderating the Health and Safety Outcomes of Job Insecurity. Journal of Safety Research, 56, 47-56. https://doi.org/10.1016/j.jsr.2015.11.003

Qing, M., Asif, M., Hussain, A., \& Jameel, A. (2019). Exploring the Impact of Ethical Leadership on Job Satisfaction and Organizational Commitment in Public Sector Organizations: The Mediating Role of Psychological Empowerment. Review of Managerial Science, 14, 1405-1432. https://doi.org/10.1007/s11846-019-00340-9

Reimer, H., Shavitt, S., Koo, M., \& Markus, H. R. (2014). Preferences Don't Have to Be Personal: Expanding Attitude Theorizing with a Cross-Cultural Perspective. The Psychological Review, 121, 619-648. https://doi.apa.org/doi/10.1037/a0037666

Reynolds, S. J. (2008). Moral Attentiveness: Who Pays Attention to the Moral Aspects of Life? Journal of Applied Psychology, 93, 1027-1041.

https://doi.apa.org/doi/10.1037/0021-9010.93.5.1027

Schuh, S. C., Zhang, X., \& Tian, P. (2013). For the Good or the Bad? Interactive Effects of Transformational Leadership with Moral and Authoritarian Leadership Behaviors. Journal of Business Ethics, 116, 629-640. https://doi.org/10.1007/s10551-012-1486-0 
Shahid, M. N. et al. (2012). Work Stress and Employee Performance in Banking Sector Evidence from District Faisalabad Pakistan. Asian Journal of Business and Management Sciences, 1, 38-48.

Shukla, A., \& Srivastava, R. (2016). Development of Short Questionnaire to Measure an Extended Set of Role Expectation Conflict, Coworker Support and Work-Life Balance: The New Job Stress Scale. Cogent Business \& Management, 3, Article No. 1. https://doi.org/10.1080/23311975.2015.1134034

Söderfjell, S. (2012). Behovsanpassat ledarskap: Att skapa förutsättningar för motivation, prestation och välbefinnande. Stockholm: Nomen.

Sparks, J., \& Hunt, S. (1998). Marketing Researcher Ethical Sensitivity: Conceptualization, Measurement, and Exploratory Investigation. Journal of Marketing, 62, 92-109. https://doi.org/10.1177\%2F002224299806200207

Tafvelin, S., von Thiele Schwarz, U., \& Stenling, A. (2019). Leadership Training to Increase Need Satisfaction at Work: A Quasi-Experimental Mixed Method Study. Frontiers in Psychology, 10, Article No. 2175. https://doi.org/10.3389/fpsyg.2019.02175

Tepper, B. J. (2007). Abusive Supervision in Work Organizations: Review, Synthesis, and Research Agenda. Journal of Management, 33, 261-289.

https://doi.org/10.1177\%2F0149206307300812

Trevino L. K., Brown M., \& Hartman L. P. (2003). A Qualitative Investigation of Perceived Executive Ethical Leadership: Perceptions from Inside and Outside the Executive Suite. Human Relations, 56, 5-37. https://doi.org/10.1177/0018726703056001448

Waldman, D. A., \& Galvin, B. M. (2008). Alternative Perspectives of Responsible Leadership. Organizational Dynamics, 37, 327-341. https://doi.org/10.1016/j.orgdyn.2008.07.001

Westfall, P. H., \& Henning, K. S. S. (2013). Texts in Statistical Science: Understanding Advanced Statistical Methods. Boca Raton, FL: Taylor \& Francis.

Winter, S. G. (2013). Habit, Deliberation, and Action: Strengthening the MICRO-Foundations of Routines and Capabilities. Academy of Management Perspectives, 27, 120137. https://doi.org/10.5465/amp.2012.0124

Wright, T. A., \& Bonett, D. G. (2002). The moderating Effects of Employee Tenure on the Relation between Organizational Commitment and Job Performance: A Meta-Analysis. Journal of Applied Psychology, 87, 1183-1190. https://doi.apa.org/doi/10.1037/0021-9010.87.6.1183

Yang, Q., \& Wei, H, (2017). The Impact of Ethical Leadership on Organizational Citizenship Behavior. The Moderating Role of Workplace Ostracism. Leadership and Organizational Development Journal, 39, 100-113. https://doi.org/10.1108/LODJ-12-2016-0313

Yukl, G. (2013) Leadership in Organizations (8th ed.). London: Pearson. 